\title{
A Influência da Taxa de Câmbio e Renda Mundial Sobre as Exportações Brasileiras de Soja $(2000-2015)^{1}$
}

\author{
Francisco Laercio Pereira Braga ${ }^{2}$ e Ana Claudia Sampaio de Oliveira ${ }^{3}$
}

\begin{abstract}
Resumo: Este trabalho propõe-se a testar a possível existência de uma relação de longo prazo entre as variáveis taxa de câmbio e renda mundial sobre o desempenho das exportações brasileiras de soja. Para este fim, estima-se um modelo econométrico capaz de descrever o nível de sensibilidade (elasticidade) das variáveis explicativas entre janeiro de 2000 e dezembro de 2015. A estratégia empírica adotada foi o uso dos métodos de séries temporais, teste de raiz unitária, teste de cointegração de Johansen, modelo vetorial autorregressivo (VAR) mais completo, denominado modelo vetor de correção de erros (VECM), a função impulso-resposta e a decomposição dos erros de previsão da variância. Os resultados demonstraram que apenas a variável renda mundial mostrou-se relevante para explicar as oscilações ocorridas ao longo do tempo na variável dependente exportação de soja, revelando a importância da conjuntura internacional para as vendas brasileiras da commodity. A variável taxa de câmbio apresentou sinal contrário à teoria econômica; contudo, registrou um coeficiente significativo. Na análise de curto prazo, observou-se que existe certa defasagem de tempo para que os desequilíbrios ocorridos no curto prazo sejam corrigidos no longo prazo.
\end{abstract}

Palavras-chaves: Exportação de soja, renda mundial, modelo VEC.

Abstract: This paper proposes to test the possible existence of a long-term relationship between the exchange rate and world income variables on the performance of Brazilian soybean exports. For this purpose, an econometric model capable of describing the level of sensitivity (elasticity) of the explanatory variables between January 2000 and December 2015 is estimated. The empirical strategy adopted was the use of time series methods, unit root test, Johansen cointegration test, autoregressive vector model (VAR), called error correction vector model (VECM), impulse-response function and the decomposition of variance prediction errors. The results showed that only the global income variable was relevant to explain the oscillations that occurred over time in the dependent soybean export variable, revealing the importance of the international scenario for the Brazilian sales of the commodity. The variable exchange rate showed a sign contrary to economic theory; however,

1. Data de submissão: 8 de fevereiro de 2017. Data de aceite: 26 de fevereiro de 2018.

2. Universidade Estadual do Ceará. Fortaleza, Ceará - Brasil. E-mail: laercio.braga@uece.br

3. Universidade Federal do Ceará. Fortaleza, Ceará - Brasil. E-mail: anasampaio2812@gmail.com 
it registered a significant coefficient. In the short-term analysis, it was observed that there is a certain time lag for short-term imbalances to be corrected in the long run.

Key-words: Soybean export, world income, VEC model.

Classificação JEL: C10, C32, F10, Q17.

DOI: http://dx.doi.org/10.1590/1234-56781806-94790560407

\section{Introdução}

A conjuntura econômica nacional vem passando por transformações importantes, como o enfrentamento à competitividade asiática, o processo de desindustrialização e a reprimarização da pauta exportadora brasileira. Nesse contexto, é fácil compreender porque a China vem despontando como importante parceiro comercial brasileiro na última década, o que fez a corrente de comércio Brasil-China alcançar níveis recordes a partir de 2011, com forte concentração na participação de produtos básicos na pauta exportadora (MELO e HOLANDA, 2013).

Destarte, o artigo analisa se as variáveis econômicas, taxa de câmbio e renda mundial, foram importantes para o crescimento das exportações de soja brasileiro no mercado internacional entre janeiro de 2000 e dezembro de 2015. Assim, o presente trabalho propõe-se a testar a possível existência de uma relação de longo prazo entre as variáveis sobre o desempenho das exportações brasileiras de soja. Para este fim, estima-se um modelo econométrico capaz de descrever o nível de sensibilidade (elasticidade) das variáveis explicativas no período em questão.

A relevância para tal estudo pauta-se, inicialmente, pela expansão da atividade agrícola e de mudanças macroeconômicas significativas ocorridas a partir da década de 1990 no cenário nacional. Contudo, percebe-se, ainda, a necessidade de estudos que analisem o impacto das principais variáveis macroeconômicas, como o câmbio e a renda dos países compradores dos produtos nas exportações do País. Diante desse pano- rama, é de conhecimento que fatores que impactam significativamente as exportações, em geral, podem não afetar com a mesma intensidade as exportações de um produto específico, no caso, a soja brasileira. Em seguida, a produção da oleaginosa, em especial, tem papel importante na economia brasileira, sobretudo no que se refere à geração de divisas para o País, pois, entre 2000 e 2015, a receita obtida com as exportações brasileiras de soja (em dólar) tiveram elevação de $860 \%$, com média de crescimento de $18 \%$ ao ano (BRASIL, 2016).

$\mathrm{O}$ artigo, além desta introdução, tem um resgate teórico sobre os trabalhos desenvolvidos envolvendo modelos econométricos e dinâmica recente da soja no mercado externo. Em seguida, são apresentados os aspectos metodológicos adotados, com natureza, fonte dos dados e métodos de análise. Na terceira etapa, estão os resultados e suas discussões. Por fim, nas últimas seções, têm-se as conclusões do estudo e as referências bibliográficas.

\section{Estudos sobre os modelos teóricos}

Os trabalhos desenvolvidos por Braga e Markwald (1983) e Zini Júnior (1988) têm em comum, primeiramente, o estabelecimento inicial da suposição de equilíbrio entre oferta e demanda e, em seguida, a imposicão de uma dinâmica de desequilíbrio. Os modelos advindos destes estudos são estimados por meio do uso do método de equações simultâneas, como mínimos quadrados de três estágios, que partem do pressuposto que as séries temporais são estacionárias. 
Os estudos de Portugal (1993), por sua vez, mostram que a estimação das equações de demanda e oferta para exportação e importação eram baseadas nas seguintes hipóteses: (a) substituição imperfeita (leve diferenciação entre produtos domésticos e estrangeiros); (b) preços diferenciados; (c) hipótese do país pequeno (a participação do país no comércio mundial é pequena).

Segundo Maia e Lima (2004, p. 7), a análise de um modelo econométrico estrutural deve ter por base, necessariamente, seu arcabouço teórico com objetivo primordial "[...] captar os efeitos marginais e as elasticidades das interações de variáveis exógenas em relação às variáveis endógenas". Assim, nesse quadro, cada grupo de modelo será considerado mais adequado, ou não, para responder a determinados questionamentos, haja visto o consenso quanto à não existência de um modelo que seja universalmente aceito.

No modelo keynesiano simplificado, o objeto de destaque está na introdução imediata do setor externo como elemento da demanda agregada por meio das exportações, bem como de um elemento de vazamento da renda, as importações. O primeiro componente, a exportação $(X)$, depende, fundamentalmente, da renda do resto do mundo $\left(Y_{x}\right)$ e da taxa de câmbio $(\theta)$, enquanto o segundo elemento, a importação $(M)$, é considerado como função crescente apenas da renda interna, numa proporção fixa, dada pela propensão marginal a importar $(m)$ (OLIVEIRA et al., 2015).

A renda do resto mundo pode ser considerada uma variável de choque externo à economia de um país. Contudo, a presença de choques frequentes torna-se relevante para os países em desenvolvimento, cuja instabilidade advinda de choques externos é uma tarefa árdua de promoção do crescimento (COSTA JUNIOR, 2013). Esse quadro intensifica-se quando os países são dependentes de exportações de commodity ou que tenham cestas de vendas externas mais limitadas, pois acabam sensíveis a instabilidades que possam aparecer na demanda global, incluindo a renda dos principais parceiros comerciais do país.

A renda externa é, ainda, uma das principais variáveis responsável pelas exportações domésticas e atua diretamente sobre a demanda dos outros países, considerando-se a demanda por bens normais. Logo, tem-se uma relação direta entre as exportações locais e a renda externa, ou seja, se ocorrer um aumento da renda de um país espera-se, ao final, um efeito posi- tivo na demanda por bens produzidos no exterior (RAMALHO e TARGINO, 2004).

A taxa de câmbio pode ser apontada como outra variável que influencia fracamente ou fortemente o desempenho de um país no comércio mundial, pois é identificada como principal caminho para alcançar maior competitividade internacional. Dessa maneira, alterações na taxa podem influenciar o desempenho dos fluxos comerciais, dado que afeta as decisões de oferta e demanda na economia (CARNEIRO, 2013).

A importância da taxa de câmbio real efetiva está vinculada ao fato de um país não possuir apenas um único parceiro, mas comercializar com vários outros distintos. Desse modo, a taxa de câmbio efetiva pode ser entendida como a média ponderada das várias taxas de câmbio reais, com seus pesos definidos de acordo com a importância de cada parceiro no comércio internacional (OLIVEIRA et al., 2015).

Diante deste cenário teórico, a análise do desempenho das exportações brasileiras no período de 1977 a 1996, desenvolvida por Cavalcanti e Ribeiro (1998), mostrou que, para os produtos básicos, semimanufaturados e manufaturados, as exportações dependiam, principalmente, das condições de demanda do mercado internacional, tais como: renda mundial e preços dos produtos exportados relativamente aos bens substitutos. Por outro lado, as vendas externas dos produtos industriais são afetadas por fatores ligados à oferta: taxa de rentabilidade e capacidade produtiva. Por fim, as exportações de produtos industrializados são influenciadas pelo nível de comércio externo. Os autores utilizaram como método econométrico o modelo VAR (Vector Autoregressive Analysis) para mensurar o impacto sobre as exportações.

Se existir uma verdadeira simultaneidade entre um conjunto de variáveis, todas elas devem ser tratadas igualmente, ou seja, não pode haver qualquer tipo de distinção entre as variáveis edógenas e exógenas. Portanto, o modelo VAR pode ser considerado simples, sem ocorrer preocupações em quais variáveis são endógenas e exógenas (GUJARATI, 2006).

Outros autores trabalharam nos estudos sobre os efeitos da renda externa, taxa de câmbio real efetiva e do preço de exportação de commodities como grãos de café e açúcar. Silva e Maia (2003) utilizaram o modelo VAR para grãos de café no período de 1961 a 2011 e chegaram a algumas conclusões pertinentes. Primeira, que o valor das exportações do café foi mais impactado 
pelos choques no preço do café em gãos e da renda externa do que pelos choques na taxa de câmbio real. Segunda conclusão, diagnosticaram, ainda, que as inovações na renda externa tiveram efeitos positivos nas exportações da commodity brasileira a curto prazo.

Alves e Bachi (2004) optaram por estimar uma função de oferta de exportação brasileira de açúcar para o período de 1995 a 2002 e também utilizaram a metodologia VAR. Dentre os resultados, os autores perceberam que as exportações brasileiras de açúcar elevaram-se à medida que a moeda nacional desvalorizou-se perante o dólar norte-americano e que o efeito da taxa de câmbio sobre o quantum exportado é mais expressivo após três meses de choque. Com o uso da metodologia VAR/ VECM para o açúcar bruto brasileiro, sendo consideradas as propriedades de integração e cointegração das séries utilizadas, Silva e Bachi (2005) demosntraram que as exportações do produto em estudo dependem primordialmente das condições do mercado externo, da taxa de câmbio e do preço doméstico.

O impacto da taxa de câmbio sobre as vendas de produtos agrícolas brasileiros no mercado internacional, por exemplo, foi analisado em dois períodos diferentes por Maia (2003). O primeiro período compreendeu o intervalo de janeiro de 1980 até dezembro de1990, enquanto o segundo iniciou-se em janeiro de 1990 e foi até dezembro de 2001. Para os objetivos propostos, o autor usou a abordagem de macroeconomia aberta a partir do modelo Mundell-Fleming e, em termos metodológicos, o modelo VAR com causalidades contemporâneas como modelo teórico. Os principais resultados obtidos revelaram que a taxa de câmbio apresentou-se significativa na determinação das exportações agrícolas brasileiras, tanto no curto como no longo prazo.

\section{A dinâmica recente da soja no comércio exterior}

O consumo de soja em grãos no mundo vem registrando crescimento expressivo na última década, que pode ser associado ao crescimento da população mundial e ao aumento do poder aquisitivo das pessoas, em especial nos países em desenvolvimento como a China, Índia e Brasil. Paralelamente, a produção mundial apresentou momentos de altos e baixos entre 2000 e 2015. Nesse mesmo intervalo, a produção de soja em grãos aumentou cerca de $100 \%$, enquanto que, entre 2011 e 2016, a expectativa de crescimento foi de 33\%, saindo de 240 milhões para 320 milhões de toneladas em agosto de 2016 (Tabela 1).

Neste cenário, os Estados Unidos despontam como grande produtor mundial de soja em grãos nas duas últimas safras do período considerado, com crescimento de 26\% em 2016 face à safra de 2011/12. O Brasil, com 97 milhões de toneladas, conseguiu elevar em $46 \%$ a produção de soja na comparação com a temporada de 2011/12.

Dados do World Bank (2013) mostram que, nos anos de 1980, 1990 e 2000, os preços da soja no mercado internacional registraram valores de US\$296,00, US\$247,00 e US\$212,00 por tonelada, respectivamente. De 2000 a 2015, o preço dessa mercadoria oscilou em determinados períodos, com destaque para o período de 2006-2008, quando ocorreram taxas de crescimento mais significativas. Em 2009, houve queda de 16,49\% em relação ao ano anterior, influenciada por fatores externos como a crise econômica mundial e a consequente redução da demanda por essa commodity. Em 2012 , os preços se elevaram em $42 \%$, revelando a recu-

Tabela 1. Mundo: produção de soja (milhões de toneladas)

\begin{tabular}{lcccccc}
\hline & $\mathbf{2 0 1 1} / \mathbf{1 2}$ & $\mathbf{2 0 1 2 / 1 3}$ & $\mathbf{2 0 1 3 / 1 4}$ & $\mathbf{2 0 1 4 / 1 5}$ & $\mathbf{2 0 1 5 / 1 6}$ agosto & Variação (2016/2011) \\
\hline Estados Unidos & 84,29 & 82,79 & 91,39 & 108,01 & 106,59 & $26 \%$ \\
Brasil & 66,50 & 82,00 & 86,70 & 94,50 & 97,00 & $46 \%$ \\
Argentina & 40,10 & 49,30 & 53,50 & 60,80 & 57,00 & $42 \%$ \\
\hline Subtotal dos 3 principais & $\mathbf{1 9 0 , 8 9}$ & $\mathbf{2 1 4 , 0 9}$ & $\mathbf{2 3 1 , 5 9}$ & $\mathbf{2 6 3 , 3 1}$ & $\mathbf{2 6 0 , 5 9}$ & $\mathbf{3 7 \%}$ \\
\hline China & 14,49 & 13,05 & 12,20 & 12,35 & 11,50 & $-21 \%$ \\
Índia & 11,70 & 12,20 & 9,50 & 9,80 & 11,50 & $-2 \%$ \\
Paraguai & 4,04 & 8,20 & 8,19 & 8,40 & 8,80 & $118 \%$ \\
Canadá & 4,47 & 5,09 & 5,36 & 6,05 & 6,20 & $39 \%$ \\
Outros & 14,84 & 16,20 & 16,41 & 19,45 & 21,46 & $45 \%$ \\
Total & $\mathbf{2 4 0 , 4 3}$ & $\mathbf{2 6 8 , 8 3}$ & $\mathbf{2 8 3 , 2 5}$ & $\mathbf{3 1 9 , 3 6}$ & $\mathbf{3 2 0 , 0 5}$ & $\mathbf{3 3 \%}$ \\
\hline
\end{tabular}

Fonte: USDA, 2015 apud Conab, 2015. Elaboração própria. 
Figura 1. Evolução do Preço médio da Tonelada da Soja no Mercado Mundial (em US\$)

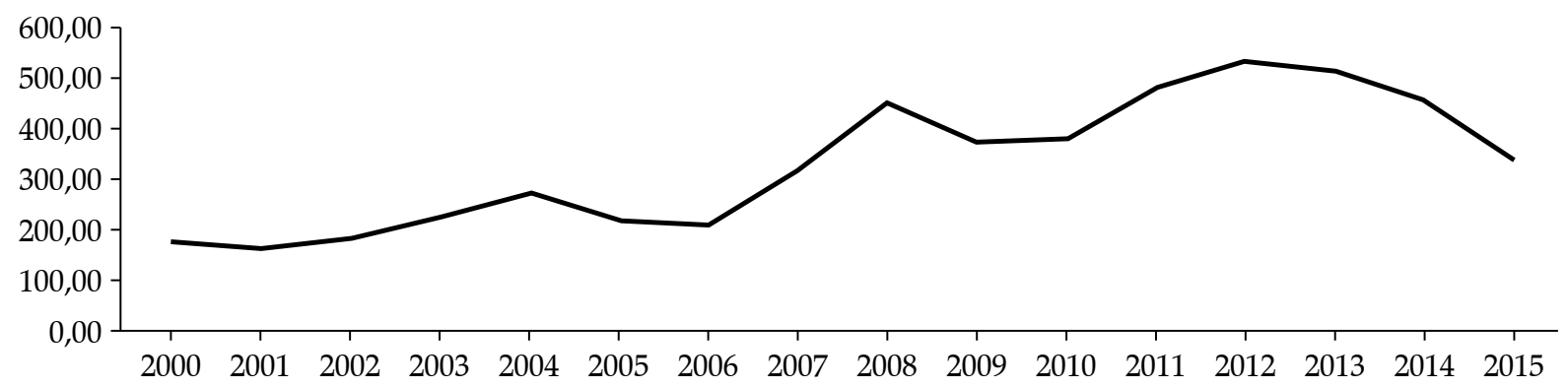

Fonte: Indexmundi, 2016. Elaboração própria.

peração no mercado mundial. Contudo, a partir desse último ano, os preços começaram uma trajetória de queda (Figura 1).

A patir da década de 2000, constatou-se, também, que o comércio externo brasileiro registrou modificações importantes na estrutura de suas pautas de exportação e importação. A intensidade tecnológica dos produtos brasileiros transacionados no mercado mundial apresentou parcela crescente negativa nos saldos dos setores classificados como de alta intensidade tecnológica, média alta e média baixa e resultado positivo apenas para os setores classificados como de baixa intensidade tecnológica (BRASIL, 2016). De fato, a pauta exportadora nacional registrou movimento em direção à primarização com a China, o qual despontou como principal responsável por esse efeito. Dessa forma, notou-se a elevação da participação de produtos básicos direcionados ao mercado chinês, concentrando-se em minérios de ferro, soja e óleos brutos de petróleo (MELO e HOLANDA, 2013).

Assim, diante deste contexto, a produção de soja aparece com papel importante na economia brasileira, sobretudo no que se refere à geração de divisas para o País. Portanto, nota-se que a soja é uma commodity agrícola que, no último decênio, sustentou a demanda dinâmica no mercado mundial. Essa característica do produto confere grande oportunidade para a expansão da produção nacional na medida em que este é destinado, fundamentalmente, ao mercado externo. A partir de 2010, as exportações brasileiras de soja tiveram como principal destino a China, que adquiriu $75 \%$ dos embarques totais de soja do Brasil em 2015. Outros países adquiriram esse produto com menor representatividade, como a Espanha, que participou com $4 \%$ das compras, e Tailândia, com 3\% (BRASIL, 2016).
Entre 2000 e 2015, a receita obtida com as exportações brasileiras de soja subiu $860 \%$, uma média de crescimento de $18 \%$ ao ano, com o maior valor exportado em 2014. Ja com relação ao volume, $(\mathrm{kg})$, o crescimento foi de $372 \%$ no mesmo intervalo de tempo, com média de crescimento em torno de $10 \%$ ao ano. Enquanto o preço médio (US\$ $/ \mathrm{kg}$ ) das exportações de soja, no mesmo período citado, passou de 0,19 para 0,39 no final de 2015 , com elevação superior a $100 \%$ (BRASIL, 2016).

Paralelamente ao crescimento das exportações de soja, tanto em valores quanto em volume, foram registradas modificações importantes no ambiente econômico nacional. Na verdade, nas décadas de 1990, 2000 e na primeira metade dos anos 2010, a economia brasileira passou por diversas transformações importantes que marcaram uma nova fase na economia nacional, tais como: processo de abertura comercial da economia brasileira, implantação do Plano Real, maior flexibilidade em relação ao movimento internacional de capitais e liberalização do mercado de câmbio.

Desta forma, constata-se que a expansão da demanda mundial por soja, notadamente da China, foi decisiva para a ascensão dos preços desse produto no mercado internacional. As exportações desta commodity brasileira para a China e para o mundo, entre 2000 e 2015, estiveram focadas no produto soja, mesmo triturada, exceto para semeadura ${ }^{4}$. Assim, regiões que até então não eram tradicionais produtoras de soja no cenário nacional, como Bahia, Maranhão e Piauí,

4. Produto representado pela numeração de oito dígitos (12019000) correspondente à Nomenclatura Comum do Mercosul (NCM) (BRASIL, 2017). 
ganharam destaque nos últimos anos como grandes exportadores.

As tradicionais regiões exportadoras de soja no Brasil são Centro-Oeste e Sul. No entanto, a segunda perdeu participação em receita em 2015, em comparação ao ínicio da série. A perda de participação também ocorreu para as vendas da região Sudeste, que saíram de $12 \%$,em 2000, para 9\% em 2015. No caminho inverso, tem-se o ganho de mercado da soja das regiões Norte e Nordeste do País (Tabela 2).

Contudo, alguns gargalos podem comprometer as transações externas dessa mercadoria e, por conseguinte, o aproveitamento das oportunidades internacionais que ora se apresentam. Dentre estes gargalos, destaca-se a precariedade da logística de escoamento da produção, tanto rodoviária quanto portuária. A precariedade reflete em cancelamento de encomendas contratadas e não entregues no prazo (MELO, BRAGA e HOLANDA, 2013).

\section{Metodologia}

Nas seções que se seguem, será possível encontrar conceitos importantes para o desenvolvimento do objeto deste ensaio. Dessa maneira, além da apresentação da natureza e fonte dos dados analisados, tem-se uma breve exposição do modelo teórico selecionado, que servirá para indicar prováveis restrições sobre as equações do modelo. No corpo metodológico estão, ainda, alguns conceitos teóricos pertinentes ao método de análise dos dados baseados, dentre outros, no trabalho de Oliveira et al. (2015).

\subsection{Natureza e fonte dos dados}

A análise do trabalho será realizada, primeiramente, com dados de origem secundária referente às exportações do produto soja, mesmo triturada, exceto para semeadura, sendo esses distribuídos em frequência mensal que se estende de janeiro de 2000 a dezembro de 2015, e foram extraídos do Ministério da Indústria e Comércio (MDIC), através do sistema Alice Web, que classifica os setores em dois dígitos (01 a 99) e segue a metodologia da Nomenclatura Comum do Mercosul (NCM). O produto soja está incluído no setor 12 (sementes e frutos oleaginosos, grãos), segundo a NCM.

O marco teórico deste trabalho é de um modelo de economia aberta (IS-LM-BP) com variáveis para compor o conjunto de dados na formulação desse modelo a saber: exportação de soja, mesmo triturada, exceto para semeaduras ( $\left.x \_s o j a\right)$, que é a variável dependente do modelo; renda mundial ( $r \_$mund) e taxa de câmbio efetiva real $\left(t_{-} c a m b\right)$, variáveis independentes. Destaca-se, ainda, o fato de que todas as variáveis são trabalhadas em logaritmo natural, dada a praticidade na estimação das elasticidades parciais e para reduzir a variabilidade

Tabela 2. Brasil: participação em receita nas exportações de soja segundo região (2000-2015) (\%)

\begin{tabular}{lccccc}
\hline & Sul & Nordeste & Sudeste & Centro-Oeste & Norte \\
\hline 2000 & 46 & 6 & 12 & 36 & 0 \\
2001 & 46 & 4 & 10 & 41 & 0 \\
2002 & 42 & 4 & 11 & 42 & 1 \\
2003 & 48 & 4 & 7 & 39 & 1 \\
2004 & 39 & 6 & 12 & 41 & 2 \\
2005 & 20 & 7 & 10 & 58 & 4 \\
2006 & 25 & 6 & 10 & 55 & 4 \\
2007 & 44 & 6 & 5 & 42 & 3 \\
2008 & 34 & 8 & 6 & 48 & 4 \\
2009 & 34 & 9 & 6 & 48 & 4 \\
2010 & 39 & 10 & 6 & 42 & 4 \\
2011 & 40 & 10 & 6 & 41 & 5 \\
2012 & 32 & 11 & 8 & 45 & 4 \\
2013 & 38 & 8 & 9 & 41 & 5 \\
2014 & 35 & 8 & 8 & 44 & 6 \\
\hline
\end{tabular}

Fonte: Brasil, 2016. Elaboração própria. 
das séries originais. A hipótese subjacente é de que as variáveis macroeconômicas citadas são relevantes para explicar o crescimento das exportações de um produto específico - no caso, a soja brasileira.

A série de exportação de soja (x_soja) foi deflacionada pelo IPA, Índice de Preços por Atacado da China, principal parceiro comercial do Brasil, que consumiu mais de $75 \%$ da soja brasileira, divulgado pelo National Statistcs Republic of China, período-base 2011. Deve-se salientar que a opção em se utilizar o IPA em vez de um Índice de Preço ao Consumidor (IPC) deve-se ao fato de refletir a evolução dos preços de produtos industriais e agrícolas que podem ser caracterizados como comercializáveis com o resto do mundo (tradeable), enquanto o segundo índice inclui bens e serviços que estão à margem do comércio internacional (non-tradeable) (ZINI, 1993, p. 32 apud MARGARIDO, 2001),

Como proxy para a renda mundial $\left(r_{-}\right.$mund), utilizou-se a soma dos produtos internos brutos (PIB's) em valores reais dos dois principais países importadores da soja brasileira (China e Espanha) que, juntos, importaram 79\% do produto nacional em 2015. É importante frisar que, como os dados dos respectivos PIB's estão disponíveis apenas trimestralmente, optou-se, desta forma, em considerar uma taxa de crescimento constante a cada três meses para que os mesmos fossem transformados em uma série mensal, conforme metodologia de Nakabashi, Cruz e Scatolin (2008).

E, finalmente, como proxy para a taxa de câmbio, este trabalho se propôs a formular uma série para a taxa de câmbio efetiva real ( $\left.t_{-} c a m b\right)$. Deve-se salientar que a política cambial impacta tanto sobre as importações quanto exportações via setor externo do País. Os dados referentes à taxa de câmbio são oriundos do Instituto de Pesquisa Econômica Aplicada (Ipea). Espera-se, ao final, que choques positivos na renda mundial e na taxa de câmbio gerem impactos positivos nas exportações de soja.

Para a metodologia de cálculo da taxa de câmbio efetiva real, considerou-se uma taxa de câmbio efetiva real cotada de forma direta, ou seja, quantidade de moeda nacional por unidade de moeda estrangeira, transformada em índice. Vale ressaltar que a escolha pela transformação em índice deve-se à inexistência de unidade de medida da variável taxa de câmbio efetiva real. Destaca-se, ainda, a ideia de que "[...] quanto maior (ou menor) é este índice, mais (ou menos) desvalorizada está a moeda doméstica em termos reais" (LAMAS, 2006, p. 72).

Posteriormente, foram estabelecidas as ponderações dos dois países que são os maiores parceiros comerciais - China e Espanha - por destino das exportações, em valor, no período de jan/2000 a dez/2015, com dados da AliceWeb, do Ministério do Desenvolvimento, Indústria e Comércio Exterior (BRASIL, 2016). A escolha de apenas dois destinos pauta-se pela representatividade conjunta dos dois países.

Outro importante passo na construção de uma taxa de câmbio efetiva real é a escolha do deflator mais adequado. Para tanto, respeitando-se as restrições quanto à disponibilidade e uniformização dos dados para cada país, foram utilizados os Índices de Preços por Atacado (IPA) conforme a metodologia utilizada por instituições brasileiras, como o Ipea (OLIVEIRA et al., 2015). De tal modo, a fórmula utilizada para calcular o índice taxa de câmbio efetiva real pode ser representada por:

$$
T_{-} C A M B t=\frac{\prod_{i=1}^{2}\left(e_{i t} P_{i t}^{*}\right)^{w i t}}{P_{i t}}
$$

Em que:

T_CAMBt - Taxa de câmbio efetiva real no período $t$;

$\Pi$ - operador do produtório;

$w_{i t}$ - o peso do país i em relação aos dois países no período $t$;

$e_{i t}-$ taxa de câmbio nominal do país i no período $t$;

$P^{*}$ - nível de preços do país i no período $t$; e

$P_{i t}$ - nível de preços do Brasil no período $t$.

\subsection{Tratamento e limitação dos dados}

Todas as observações coletadas foram selecionadas a partir dos bancos de dados e nas pesquisas de órgãos internacional e nacional, e foram, assim, ajustadas com a finalidade de atender aos questionamentos levantados aos objetivos do presente trabalho. $\mathrm{O}$ método de tratamento utilizado será, sobretudo, por meio de análise de conteúdo gráfico e econométrico. Já a análise empírica foi realizada através da utilização de regressões econométricas e por métodos de defasagens distribuídas para analisar o impacto do crescimento da renda externa dos dois principais parceiros comerciais do Brasil e taxa de câmbio. A inclusão das defasagens deve-se à existência de certa discrepância entre 
mudanças no câmbio e renda dos parceiros comerciais sobre as exportações.

No que se refere à limitação da pesquisa, pode-se apontar a abrangência temporal que está restrita ao período analisado (2000-2015), pois foi nesse período que presenciou-se uma mudança significativa, com a inserção de um importante player no comércio internacional (China) como principal demandante da soja brasileira.

\subsection{Modelo teórico}

As funções de exportação e importação de um determinado produto estão representadas, aqui, nas equações (2) e (3). Na equação (2) é possível verificar que a exportação de soja é definida como função dependente da taxa de câmbio efetiva real (t_camb) e da renda externa mundial ( $r_{-}$mund), enquanto que a importação (Eq. 3) é influenciada pela mesma taxa de câmbio e renda interna $\left(r_{-}\right.$int $)$.

$$
\begin{aligned}
& X=X\left(t_{-} \text {camb }, r_{-} \text {mund }\right) \\
& M=M\left(t_{-} \text {camb }, r_{-} \text {int }\right)
\end{aligned}
$$

O modelo mais completo de economia aberta de um país contém uma curva de equilíbrio do balanço de pagamentos, curva BP, além das curvas IS e LM. A primeira representará todas as combinações possíveis de taxa de juros e renda que levam ao equilíbrio na conta balanço de pagamentos para uma determinada taxa de câmbio (FROYEN, 2013). Dessa forma, a curva BP será representada da seguinte forma:

$X\left(t_{-}\right.$camb, r_mund $)-M\left(t_{-} c a m b, r_{-}\right.$int,$)+F\left(r, r_{x}\right)=0$

Em que: $r$ é a taxa de juros interna; $r_{x}$ é a taxa de juros internacional.

Desta equação 4, observa-se, ainda, termos referentes à balança comercial (exportações líquidas), representados por $X$ e $M$, como já mencionados anteriormente, e o termo que diz respeito à entrada líquida de capitais autônomos, no caso, o $F$ da expressão matemática (FROYEN, 2013). Assim, torna-se possível representar as relações entre o saldo da conta corrente e suas principais variáveis explicativas a partir das equações a seguir:

$$
\begin{aligned}
& C C=X-M \\
& C C=X\left(t_{-} c a m b, r \_m u n d\right)-M\left(t_{-} c a m b, r \_i n t\right)
\end{aligned}
$$

A partir das equações (5) e (6), verifica-se que as exportações são influenciadas pela taxa de câmbio efetiva real $\left(t_{-} c a m b\right)$ e da renda externa $\left(r_{-}\right.$mund), exercendo relação direta com ambas as variáveis; do lado da importação, nota-se a dependência desta variável em relação à taxa de câmbio efetiva real (t_camb) e da renda interna $\left(r_{-}\right.$int $)$. Nesse caso, constata-se que as compras exibem relação inversa com uma variável e direta com a outra, respectivamente.

Deve-se salientar que o modelo de economia aberta (IS-LM-BP) desenvolvido neste trabalho envolverá apenas um item da balança de bens, que no caso é referente à exportação de soja, registrada, por sua vez, do lado dos débitos da conta Transações Correntes. Contudo, espera-se que as relações expostas no modelo mantenham-se para este caso particular citado, assim como foi representado no modelo de Oliveira et al. (2015). Dessa maneira, a função exportação de soja como uma função linear nos logaritmos com um componente estocástico $\left(\varepsilon_{t}\right)$ pode ser representada conforme equação (7):

$$
\begin{aligned}
& \operatorname{Ln}(X M)=\beta_{0}+\beta_{1} \operatorname{Ln}\left(t_{-} c a m b\right)+ \\
& +\beta_{2} \operatorname{Ln}\left(r_{-} \text {mund }\right)+\varepsilon_{t}
\end{aligned}
$$

Em que: $X M$ são as exportações de soja e as constantes $\beta_{1}$ e $\beta_{2}$ são os coeficientes de elasticidade parcial da função de demanda mundial da soja brasileira.

A definição de elasticidade aborda não somente aspectos microeconômicos, mas, também, macroeconômicos, que relacionam tanto o preço e a quantidade demandada (ou ofertada) de um determinado produto, quanto àqueles relacionados aos níveis de renda e de compras de um dado país, sendo este o modelo utilizado conforme Oliveira et al. (2015).

A utilização de vetores autorregressivos permite expressar modelos econômicos completos e com possibilidade da estimação dos seus parâmetros. Dessa forma, trabalhar com as metodologias VAR e VECM tornou-se importante na apreciação de questões macroeconômicas. Dentre essas, a identificação da possível existência e intensidade dos resultados das variáveis taxa de câmbio e renda mundial sobre as exportações da soja nacional.

A tendência estocástica e determinística do modelo será observada a partir da análise empírica, que envolve a observação gráfica das séries. $\mathrm{Na}$ etapa seguinte, os testes para determinar a ordem 
de integração e cointegração das séries são realizados (em geral se $\mathrm{I}(0)$ ou $\mathrm{I}(1)$ ), com ou sem tendência determinística.

Após a identificação da ordem de integração das variáveis utilizadas, estima-se o modelo VAR com as defasagens adequadas para o modelo dinâmico com base em critérios de escolha. Ressalta-se que, se uma ou mais séries forem I(1), faz-se o teste de cointegração proposto por Johansen (1991) para definir a existência (ou ausência) e o número das relações de cointegração (ou, de longo prazo) entre as variáveis de estudo integradas de mesma ordem. O referido autor coloca ainda que, para testar o número dos vetores de cointegração, deve-se utilizar dois instrumentos: o teste do traço ( $\left.\lambda_{\text {trace }}\right)$ e o teste do máximo autovalor $\left(\lambda_{\max }\right)$.

Conforme Oliveira et al. (2015), caso não sejam verificadas equações de cointegração (posto nulo), deve-se estimar um VAR para as séries em primeira diferença; entretanto, sendo comprovada a existência de uma ou mais equações de cointegração, estima-se um VECM. Os conceitos de raiz unitária, critérios de seleção de modelos, cointegração, decomposição da variância do erro e função de impulso resposta estão intimamente relacionados aos aspectos teóricos do modelo VAR (FABRIS e MEURER, 2007).

$\mathrm{O}$ modelo autorregressivo de $p$-ésima ordem VAR $(p)$ por um vetor com $n$ variáveis endógenas, $Y_{t}$, estão conectados entre si por meio da matriz $A$, de acordo com a seguinte expressão:

$$
A Y_{t}=\Omega_{0}+\Phi 1 Y_{t-1}+\Phi 2 Y_{t-2}+\ldots+\Phi P Y_{t-p}+\varepsilon_{t}
$$

Em que:

$A$ - é uma matriz $\mathrm{n} \times \mathrm{n}$ que define as restrições contemporâneas entre as variáveis que constituem o vetor $\mathrm{n} \times 1, Y_{t}$;

$\Omega_{0}$ - é um vetor de constantes $\mathrm{n} \times 1$ (vetor de interceptos);

$\Phi_{p}$ - são matrizes dos parâmetros de ordem $\mathrm{n} \times \mathrm{n}$;

$e, \varepsilon_{t}$ - é um vetor $\mathrm{n} \times 1$ de perturbações aleatórias não correlacionadas entre si (termo de erro estocástico).

Destarte, as relações entre as variáveis endógenas resultante de um modelo econômico teoricamente estruturado estão representados na equação (8). Assim, a metodologia VAR pode ser estimada por meio do método de Mínimos Quadrados Ordinários (MQO), levando-se em consideração, principalmente, a interação entre as variáveis do sistema.

\subsubsection{Vetor de correção de erros (VEC)}

De acordo com a teoria abordada, o modelo original pode ser descrito na forma de um VECM (Vetor de Correção de Erros) caso as variáveis sejam estacionárias com dinâmica comum, podendo-se dizer que têm componentes tanto de longo prazo como de curto prazo. Assim, para que seja possível fazer inferências com o uso de séries temporais, faz-se necessário que os estimadores obtidos tenham propriedades desejáveis, ou seja, que as variáveis do vetor autorregressivo sejam estacionárias. Ou seja, de acordo com Pereira, Silva e Maia (2017), caso seja diagnosticada a existência de raiz unitária nas séries, a equação deve ser reparametrizada e submetida, novamente, ao teste ADF em diferenças até tornar-se estacionária.

Engle e Granger (1987, p. 253) apresentam a cointegração para uma melhor compreensão da seguinte forma: os elementos do vetor $X_{t}, \mathrm{n} \times 1$ são ditos cointegrados de ordem $(d, b)$, denotados por $X_{t} \sim C I(d, b)$ se: i) Todos os elementos de $X_{t}$ são integrados de ordem $d$, ou seja, são $\mathrm{I}(d)$; ii) Existe um vetor não nulo, $\beta$, tal que: $u_{t}=X_{t}^{\prime} \beta \sim I(d-b), b>0$. Assim, o vetor $\beta$ é chamado de vetor de cointegração.

Bueno (2011, p.204) reforça que, na primeira condição (i) "[...] todas as variáveis constantes de $X_{t}$ devem ter a mesma ordem para que possam ser cointegradas $[\ldots]]^{\prime \prime}$, ou seja, guardam uma relação de equilíbrio de longo prazo. A segunda condição (ii), diz-se que existe equilíbrio de longo prazo quando $X_{t}^{\prime} \beta=$ 0 , isto é, "[...] o vetor $\beta$, chamado vetor de cointegração, define uma combinação linear entre os elementos de $X_{t}$ perfeita no sentido de seguir uma tendência comum, sem desvio".

Desta maneira, é possível inferir que a teoria de cointegração se atenta, principalmente, a dois aspectos: o primeiro, refere-se a testar os resíduos $u_{t}$ para confirmar sua estacionariedade; e o segundo, se confirmada essa estacionariedade, utilizar a informação para melhor ajustar o modelo VAR, passando a ser denominado de modelo VEC, uma vez que ele incorpora o erro de equilíbrio, justificando, portanto, a denominação modelo vetor de correção de erros.

Os autores Campbell e Perron (1991) apresentam, por sua vez, a definição de cointegração de maneira mais ampla, no qual não impõem a restrição de mesma ordem de integração para a existência de cointegração, e complementam que basta que ocorra 
a segunda condição citada anteriormente para que os elementos de um vetor $X_{t}, \mathrm{n} \times 1$ sejam cointegradas de ordem $(d, b)$, denotados por $X_{t} \sim C I(d, b)$. Logo, nesse caso, devem existir pelo menos duas variáveis integradas de mesma ordem na ordem máxima de integração dentre todas as variáveis, para que haja cointegração. Segundo Veríssimo e Silva (2013), a vantagem dessa definição é a permissão que se tem em trabalhar modelos que relacionam variáveis não estacionárias com estacionárias.

\subsubsection{Teste de estabilidade do modelo: o Teste de Chow}

Ao se trabalhar com séries históricas de determinadas variáveis, existe um risco de estas, ao longo do tempo, apresentarem a possibilidade de quebra estrutural, o que poderá influenciar a consistência dos valores estimados e torná-los inadequados para previsões de valores de estimadores futuros.

Com o teste de Chow, estima-se o modelo desde sua observação inicial até uma data $t$. Na sequência, observa-se o erro cometido na projeção em $t+1 \mathrm{e}$ comparam-se os resíduos do período de $t=0$ até $t$, com o resíduo de $t+1$ através de um teste $\mathrm{F}$.

Gujarati (2006) coloca que as hipóteses que fundamentam o teste de Chow são duas: 1$) u_{1 t} \sim N\left(0, \sigma^{2}\right)$ e $u_{2 t}$ $\sim\left(0, \sigma^{2}\right)$, ou seja, os termos de erro nas regressões dos subperíodos se distribuem normalmente, com média zero e variância constante (homoscedástica); e 2) os dois termos de erro, $u_{1 t}$ e $u_{2 t}$, têm distribuições independentes. Assim, a mecânica do teste de Chow, com aplicação do teste $\mathrm{F}$, tem por base o uso de um modelo restrito (composto por toda a amostra) e modelos irrestritos (equações com dados dos períodos anteriores e posteriores à suposta quebra) (GUJARATI, 2006). O referido teste é definido por:

$$
F=\frac{\left(S Q R_{R}-S Q R_{S R}\right) / k}{\left(S Q R_{S R}\right) /\left(n_{1}-n_{2}-2_{k}\right)} \sim F\left[k,\left(n_{1}+n_{2}-2_{k}\right)\right]
$$

\section{Em que:}

$S Q R_{R}$ - Soma restrita dos quadrados dos resíduos da regressão de MQO da amostra completa; $S Q R_{S R}$ - Soma sem restrição dos quadrados dos resíduos de $\mathrm{MQO}$ das duas subamostras, com $n_{1}$ e $n_{2}$ dados. $k$ - número de parâmetros da equação.
Diante do que foi colocado, segue-se a análise da distribuição $F$ com $\mathrm{gl}=\left(k, n_{1}-n_{2}-2 k\right)$. Se o $F$ calculado por meio da equação (9) exceder o valor crítico de $F$ no nível escolhido $\alpha$, rejeita-se a hipótese de que as regressões (obtidas das subamostras) são iguais, ou seja, rejeita-se a hipótese de estabilidade estrutural (GUJARATI, 2006).

\section{Resultados e discussão}

A previsão de variáveis econômicas é uma parte relevante na análise da literatura sobre séries temporais. Assim, a aplicação do teste de estacionariedade das séries ou teste de raiz unitária, e o teste de estabilidade estrutural, são alguns dos instrumentos que darão respaldo à ideia básica que constitui o objeto desta seção. Ou seja, analisar a dependência estatística da variável exportação da soja brasileira em relação às variáveis taxa de câmbio efetiva real e renda mundial, ora representada pela renda dos principais países importadores da mesma commodity.

\subsection{Análise gráfica das variáveis}

Para uma análise prévia e visual dos dados expressos neste estudo, os gráficos a, b e c, dispostos na Figura 2 , demonstram a evolução das séries temporais mensais exportação de soja ( $x_{\text {_ssja }}$ ), taxa de câmbio efetiva real $\left(t_{-}\right.$camb) e renda mundial ( $r$ m mund) para o período que se estende de janeiro de 2000 a dezembro de 2015, correspondendo a um total de 192 observações para cada série.

Segundo Gujarati (2006) e Bueno (2011), uma representação gráfica dos dados é, geralmente, o primeiro passo para análise de séries temporais e a primeira impressão que se tem é de que todas as séries, embora não uniformes, parecem tender para cima ou para baixo. Na verdade, como será possível provar por meio de testes específicos, todas estas (em nível) são séries temporais não estacionárias.

O estudo empírico realizado com arrimo nos gráficos e regressões econométricas utilizou o modelo de correção de erros (VEC) para analisar o impacto das taxas de câmbio e da renda mundial sobre as exportações da soja brasileira, e teve como suporte para a análise o software econométrico Eviews 5.0. 
Figura 2. Brasil: evolução das variáveis selecionadas no período de janeiro de 2000 a dezembro de 2015
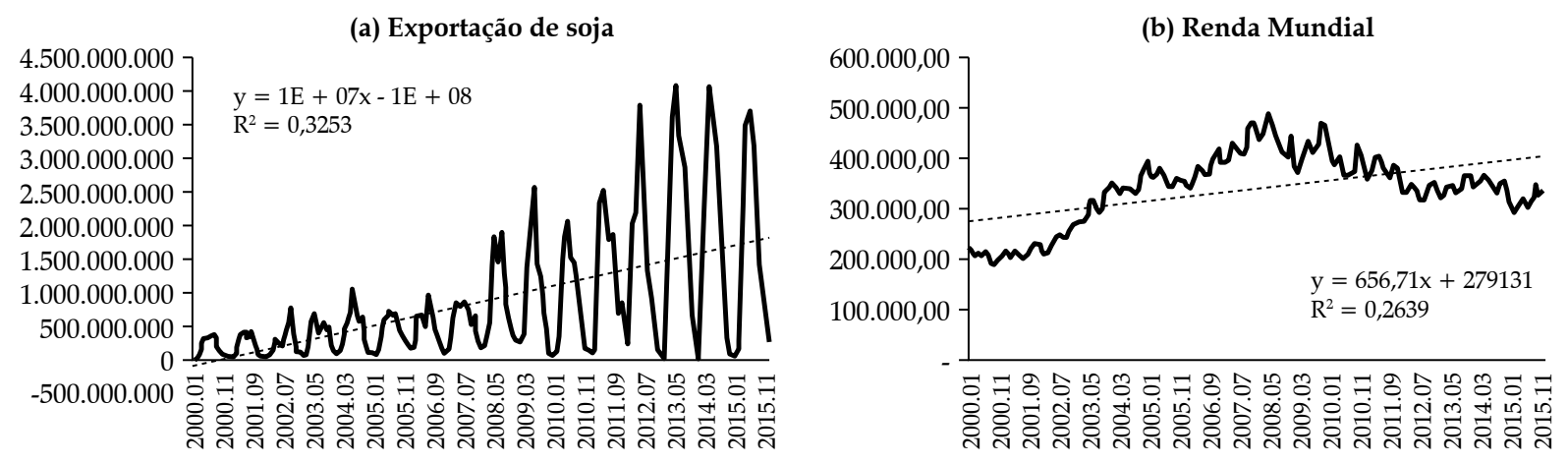

(c) Taxa de câmbio

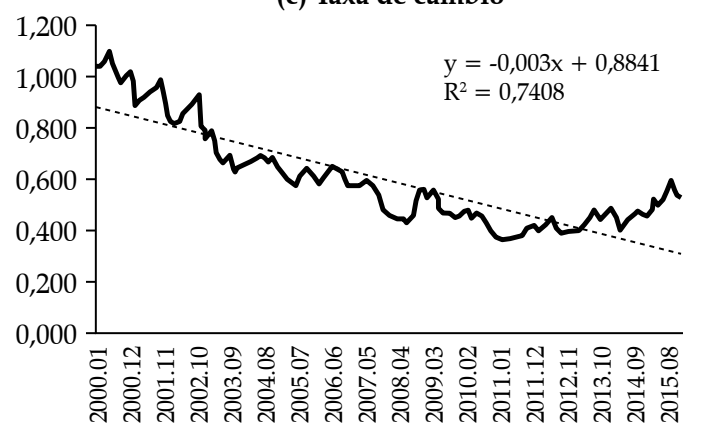

Fonte: Elaboração própria a partir dos dados da pesquisa, 2016.

\subsection{Estacionaridade das variáveis}

O primeiro passo na análise de séries temporais é verificar se elas são estacionárias, para que seja possível fazer inferências (ou previsões) e que possam ser úteis no processo de tomada de decisões nos âmbitos político e econômico, conforme Oliveira (2013). Assim, caso as séries não sejam estacionarias em nível, deve-se aplicar a primeira diferença nas mesmas para estacionarizá-las. Destaca-se que a maioria das séries econômicas é $I(1)$, ou seja, integradas de primeira ordem. Então, para verificar a estacionariedade (ou não estacionariedade) foram utilizados os seguintes testes de raiz unitária: Augmented Dickey-Fuller (ADF) ${ }^{5}$, Phillips-Perron (PP) ${ }^{6}$ e Kwiatkowski-Phillips-Schmidt-Shin (KPSS) ${ }^{7}$.

5. DICKEY, D. A. e FULLER, W. A. Distribution of the Estimators for Autoregressive Time Series with a Unit Root. Journal of the American Statistical Association, v. 74, p. 427-431.

6. PHILLIPS, P. C. B. e PERRON, P. Testing for a Unit Root in Time Series Regression. Biometrika, v. 75, 1988, p. 335-346.

7. KWIATKOWSKI, D. et al. (1992). Testing the null hypothesis of stationarity against the alternative of a unit root:
Pela análise dos testes estabelecidos, verificou-se que apenas a variável exportação de soja ( $x_{-}$soja) mostrou-se estacionária em nível para os testes ADF e PP, enquanto as demais se mostraram não estacionárias. No entanto, para o teste KPSS, a situação foi inversa, ou seja, enquanto as variáveis taxa de câmbio efetiva real $\left(t_{-}\right.$camb) e renda mundial $\left(r_{-}\right.$mund $)$ mostraram-se estacionárias, apenas a variável exportação de soja $\left(x \_s o j a\right)$ apresentou-se como não estacionária. Deve-se ressaltar, ainda, que o teste Dickey-Fuller Aumentado foi realizado com defasagens baseadas no Critério de Informação de Schwarz, conforme Modensi (2008) e Freire Jr. e Paiva (2014) (Tabela 3).

Aplicada a primeira diferença nas séries exportação de soja ( $x_{-}$soja), taxa de câmbio efetiva real (t_camb) e renda mundial $\left(r_{-}\right.$mund), as mesmas se tornaram estacionárias, conforme dados da Tabela 4.

how sure are we that economic time series have a unit root? Journal of Econometrics, v. 54, p. 159-178. 
Tabela 3. Teste de Raiz Unitária para variáveis em nível

\begin{tabular}{ccccccc}
\hline Variável & ADF & L & PP & L & KPSS & L \\
\hline __soja & $-7,804343^{\text {ns }}$ & 11 & $-17,13887^{\text {ns }}$ & 16 & $0,121936^{*}$ & 15 \\
$t$ _camb & $-2,090751^{*}$ & 1 & $-2,033611^{*}$ & 6 & $1,432606^{\text {ns }}$ & 11 \\
r_mund & $-2,447200^{*}$ & 12 & $-1,822079^{*}$ & 67 & $0,807456^{\text {ns }}$ & 11 \\
\hline
\end{tabular}

Legenda: *Indica rejeição da hipótese nula ao nível de $5 \% ; L=$ número de defasagens de cada variável.

Nota 1: $\mathrm{H}_{0}$ : a série possui uma raiz unitária, ou seja, é não estacionária.

Nota 2: Os valores críticos para o nível de significância de $5 \%$ são: $\mathrm{T}_{\mathrm{c}(\mathrm{ADF})}=-2,876595 ; \mathrm{T}_{\mathrm{c}(\mathrm{PP})}=-2,876515 ; \mathrm{T}_{\mathrm{c}(\mathrm{KPSS})}=0,463000$.

Fonte: Elaboração própria a partir dos dados da pesquisa, 2016.

Tabela 4. Teste de Raiz Unitária para variáveis em 1aㅡ diferença

\begin{tabular}{lcccccc}
\hline \multicolumn{1}{c}{ Variável } & ADF & L & PP & L & KPSS & L \\
\hline $\mathrm{D}\left(x_{-}\right.$soja $)$ & $-14,73476^{*}$ & 11 & $-135,3362^{*}$ & 188 & $0,177770^{*}$ & 60 \\
$\mathrm{D}\left(t_{-}\right.$camb $)$ & $-10,21806^{*}$ & 0 & $-9,772978^{*}$ & 14 & $0,285185^{*}$ & 5 \\
$\mathrm{D}\left(r_{-}\right.$mund $)$ & $-2,816506^{\mathrm{ns}}$ & 11 & $-12,92221^{*}$ & 104 & $0,273627^{*}$ & 100 \\
\hline
\end{tabular}

Legenda: * Indica rejeição da hipótese nula ao nível de $5 \% ; L=$ número de defasagens de cada variável.

Nota 1: $\mathrm{H}_{0}$ : a série possui uma raiz unitária, ou seja, é não estacionária.

Nota 2: Os valores críticos para o nível de significância de $5 \%$ são: $\mathrm{T}_{\mathrm{c}(\mathrm{ADF})}=-2,876595 ; \mathrm{T}_{\mathrm{c( \textrm {PP } )}}=-2,876515 ; \mathrm{T}_{\mathrm{c}(\mathrm{KPSS})}=0,463000$.

Fonte: Elaboração própria a partir dos dados da pesquisa, 2016.

Na próxima seção, será realizada a escolha do número de defasagens, a seleção da estrutura do modelo a ser testado pelo programa econométrico, a partir dos resultados obtidos no teste de cointegração de Johansen e, posteriormente, na definição do tipo de modelo a ser adotado, se VAR ou VEC, com base nos resultados do mesmo teste.

\subsection{Teste de Cointegração de Johansen}

Após a conclusão dos testes de raiz unitária, serão apresentados os testes de cointegração de Johansen. Na elaboração do teste é fundamental determinar o número de defasagens. Para isso, estimou-se um VAR irrestrito com as séries em nível, observando os critérios de Akaike (AIC), de Schwarz (SC) e de HannanQuinn (HQ) para selecionar o número de defasagens a ser empregado. Os critérios AIC e HQ sugeriram a utilização de sete (07) e quatro (04) defasagens para o modelo, respectivamente (Tabela 5).

No entanto, optou-se por trabalhar com o critério de Shwarz pois, conforme Bueno (2011), este critério é mais consistente quando se trabalha com um número significativo de amostras. Assim, tendo por base o critério de informação de Schwarz, adotou-se uma (01) defasagem no modelo.

Tabela 5. Critério de seleção da ordem de defasagens do modelo VAR para as variáveis $x_{-}$soja, t_camb e $r_{-}$mund

\begin{tabular}{ccccc}
\hline Lag & LogL & AIC & SC & HQ \\
\hline 0 & $-84,79048$ & 0,965114 & 1,035004 & 0,993441 \\
1 & 645,1834 & $-6,795472$ & $-6,446023^{*}$ & $-6,653836$ \\
2 & 669,3361 & $-6,884088$ & $-6,255079$ & $-6,629142$ \\
3 & 684,9252 & $-6,879622$ & $-5,971053$ & $-6,511368$ \\
4 & 745,6089 & $-7,365314$ & $-6,177186$ & $-6,883751^{*}$ \\
5 & 766,4661 & $-7,418110$ & $-5,950422$ & $-6,823238$ \\
6 & 787,6784 & $-7,474765$ & $-5,727518$ & $-6,766584$ \\
7 & 816,1343 & $-7,10155^{*}$ & $-5,583348$ & $-6,788665$ \\
8 & 831,2521 & $-7,600567$ & $-5,294200$ & $-6,665767$ \\
\hline
\end{tabular}

Notas: 1) * Indica a ordem selecionada pelo critério; 2) AIC = Critério de Informação de Akaike, SC = Critério de Informação de Schwarz e HQ = Critério de Informação de Hannan-Quinn.

Fonte: Elaboração própria a partir dos dados da pesquisa, 2016. 
Tabela 6. Resultado do teste de cointegração de Johansen para as variáveis $x_{-}$soja, $t \_c a m b$ e $r$ _mund (2000 a 2015)

\begin{tabular}{cccccc}
\hline $\begin{array}{c}\text { Hipótese Nula } \\
\text { (Ho) }\end{array}$ & $\begin{array}{c}\text { Hipótese Alternativa } \\
(\text { Ho) }\end{array}$ & $\begin{array}{c}\text { Estatística } \\
\lambda_{\text {traco }}\end{array}$ & $\begin{array}{c}\text { Valor Crítico } \\
\lambda_{\text {traco }}\end{array}$ & $\begin{array}{c}\text { Estatística } \\
\lambda_{\text {Míx. Autovalor }}\end{array}$ & $\begin{array}{c}\text { Valor Crítico } \\
\lambda_{\text {Máx. Autovalor }}\end{array}$ \\
\hline $\mathrm{r} \leq 0^{*}$ & $\mathrm{r}>0$ & $60,77859^{*}$ & 24,27596 & $53,82015^{*}$ & 17,79730 \\
$\mathrm{r} \leq 1$ & $\mathrm{r}>1$ & 6,958437 & 12,32090 & 6,893015 & 11,22480 \\
$\mathrm{r} \leq 2$ & $\mathrm{r}>2$ & 0,065422 & 4,129906 & 0,065422 & 4,129906 \\
\hline
\end{tabular}

Nota: Os Testes do Traço indica que há 1 equação de cointegração ao nível de $5 \%$.

Legenda: * Denota rejeição da hipótese nula ao nível de $5 \%$.

Fonte: Elaboração própria a partir dos dados da pesquisa, 2016.

Tabela 7. Estimativa de longo prazo do vetor de cointegração para o modelo de exportação de soja - 2000 a 2015

\begin{tabular}{ccc}
\hline x_soja & r_mund & t_camb \\
\hline 1,000000 & $-1,653463$ & 0,212154 \\
& $(0,13569)$ & $(0,36829)$ \\
\hline
\end{tabular}

Nota: Os valores entre parênteses representam os erros padrão das estimativas.

Fonte: Elaboração própria a partir dos dados da pesquisa, 2016.

Para testar a presença (ou não) de vetores de cointegração, os testes do traço $\left(\lambda_{\text {traço }}\right)$ e do máximo autovalor $\left(\lambda_{\text {máx }}\right)$, adotando um valor crítico tabelado ao nível de significância de $5 \%$, sugere a presença de, pelo menos, um vetor de cointegração, o que significa que as séries apresentam uma relação de longo prazo.

Na Tabelas 6 são apresentados os resultados dos testes e, como é possível observar, tanto a hipótese nula do teste do traço $\left(\lambda_{\text {trace }}\right)$, como a hipótese nula do teste do máximo autovalor $\left(\lambda_{\max }\right)$ foram rejeitadas ao nível de $5 \%$, tendo em vista que o valor calculado da estatística foi superior ao valor crítico.

Assim, como foi possível observar, o teste de cointegração de Johansen detectou a presença de um vetor de cointegração num sistema envolvendo três variáveis, podendo-se inferir que a aplicação do modelo de correção de erros (VECM) é o mais indicado para determinar o comportamento dinâmico das exportações de soja, em detrimento da aplicação do modelo vetorial autorregressivo (VAR).

\subsection{Vetor de Correção de Erros (VECM)}

Dando início à análise dos resultados referentes ao primeiro vetor de cointegração - os resultados da função de longo prazo - é possível observar que nem todos os sinais dos parâmetros são condizentes com o esperado. Ademais, os resultados demonstrados são relativos à equação de equilíbrio de longo prazo, que corresponde ao autovetor, normalizado para as exportações, assim, os sinais devem ser interpretados de maneira inversa (Tabela 7).

No que se refere à taxa de câmbio, esta não apresentou sinal de acordo com a teoria econômica, indo de encontro à chamada condição de Marshall-Lerner ${ }^{8}$, conforme Monte (2015). No entanto, tal situação corrobora com o que fora observado na Figura 1, que demonstra que as duas variáveis (exportação de soja e taxa de câmbio) caminharam, em geral, em direções opostas ao longo do período analisado.

Quanto à variável renda mundial, a análise demonstrou que a mesma afetou positivamente as exportações da soja brasileira no longo prazo e que um aumento de $1 \%$ na renda mundial poderá elevar as exportações em cerca de $1,6 \%$, o que indica uma elasticidade da renda mundial positiva. Ademais, o coeficiente estimado foi estatisticamente significativo.

Assim, os coeficientes demonstraram que existe uma relação direta entre a variável exportação de soja e a variável explicativa renda mundial, e uma relação

8. Abba P. Lerner, economista russo, estabeleceu as condições nas quais uma mudança na taxa de câmbio de um país melhoraria sua balança comercial. Esta condição é também chamada Condição Marsall-Lerner e estabelece que, supondo altos preços da elasticidade da oferta, uma desvalorização cambial melhorará a situação em conta corrente de um país se a soma das elasticidades da demanda interna por importações mais a demanda externa por exportações for maior que a unidade (SANDRONI, 2014). 
inversa entre as exportações de soja e a da taxa de câmbio, sendo que ambas se mostraram significativas.

A exemplo da análise realizada por Monte (2015), é possível inferir que o crescimento das exportações nacionais não dependerá tanto da taxa de câmbio, mas "o crescimento da renda mundial e, consequentemente, da demanda mundial" será mais significativo para explicar o resultado das exportações dessa commodity no País. Ademais, é importante mencionar que a pauta das exportações brasileiras ainda é altamente dependente das commodities e, com o crescimento de blocos econômicos como o Brics, com destaque para a China (principal importador da soja brasileira). A demanda por esse produto tem aumentado significantemente nos últimos anos, o que contribui para o incremento das exportações.

Quanto à dinâmica de curto prazo, os resultados da estimação do modelo de correção de erro mostraram que os coeficientes estimados foram significativos a $5 \%$. Ademais, observou-se que os coeficientes em análise são pequenos, demonstrando que a velocidade de ajustamento é baixa, ou seja, a correção no curto prazo se dá de maneira lenta para o equilíbrio no longo prazo (Tabela 8).
Ainda sobre a dinâmica de curto prazo, o termo de correção de erros indicou que são necessários, aproximadamente, dois períodos $(1 / 0,4750)$ para que os desequilíbrios de curto prazo sejam corrigidos em longo prazo. Assim, para a variável exportação, esses desequilíbrios são corrigidos de forma relativamente rápida, o que não acontece para as variáveis taxa de câmbio e renda mundial.

Sabendo-se que, de modo geral, não é possível identificar todos os parâmetros necessários para uma perfeita estruturação de um modelo, devido à necessidade da inclusão de infinitas restrições adicionais ao mesmo, o próximo passo será a análise das funções de resposta a impulsos, para definir o efeito de choques exógenos nas variáveis selecionadas sobre as exportações de soja. A análise das funções de impulso-resposta, por sua vez, busca verificar, principalmente, o impacto dos choques da taxa de câmbio e da renda mundial sobre as exportações de soja. Assim, como é possível observar na Figura 2, o choque não antecipado de um desvio padrão na variável renda mundial gera, inicialmente, uma queda acentuada no nível das exportações de soja da ordem de aproximadamente $0,2 \%$ já no primeiro período, seguindo, a partir daí, numa trajetória

Tabela 8. Estimativa de curto prazo dos vetores de cointegração

\begin{tabular}{ccc}
\hline D(x_soja) & D(r_mund) & D(t_camb) \\
\hline$-0,475040$ & 0,002553 & 0,002568 \\
$(0,06406)$ & $(0,00302)$ & $(0,00247)$ \\
\hline
\end{tabular}

Nota: 1) Os valores entre parênteses representam os erros padrão das estimativas; 2) $D$ = significa a primeira diferença da variável.

Fonte: Elaboração própria a partir dos dados da pesquisa, 2016.

Figura 3. Função de resposta a impulsos
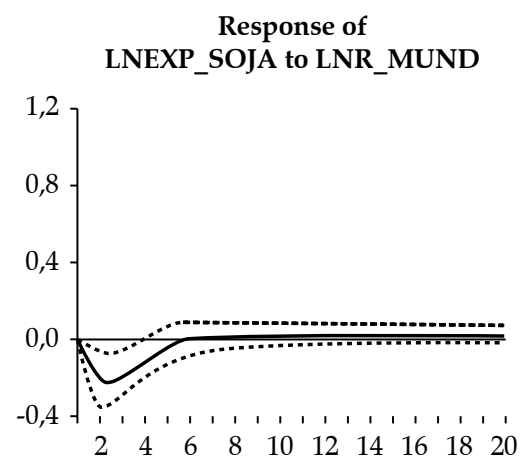

Response of LNEXP_SOJA to LNTCER

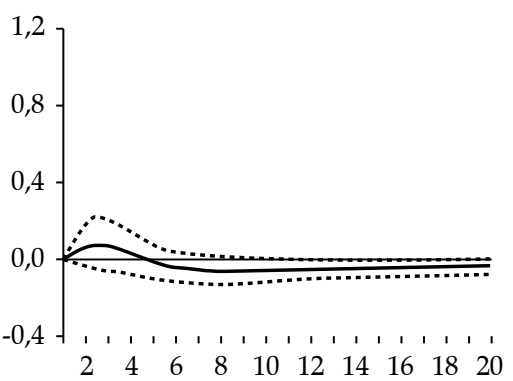

Response of LNEXP_SOJA to LNEXP_SOJA

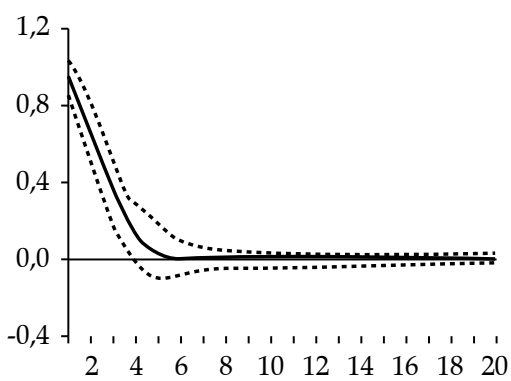

Notas: 1) LN = indica que as variáveis estão expressas em logaritmos.

Fonte: Elaboração própria a partir dos dados da pesquisa, 2016. 
ascendente até o sétimo período, quando se estabiliza. Tal trajetória permite inferir que a variável renda exerce influência sobre as exportações de soja.

Quanto à ocorrência de um choque não antecipado sobre a variável taxa de câmbio, causa um curto efeito positivo sobre as exportações somente no segundo mês após o choque e, mesmo assim, de maneira pouco significativa, vindo, no entanto, a se estabilizar.

A metodologia VECM permite, em complemento à análise das funções de impulso-resposta, a realização do exercício de decomposição da variância, com o propósito de verificar que porcentagem da variância do erro de previsão decorre de cada variável endógena ao longo do período de previsão. Na Tabela 9, são apresentados os resultados da decomposição para as exportações de soja.

Analisando os resultados da decomposição da variância dos erros de previsão para a variável exportação de soja, é possível observar que, nos primeiros períodos, a variância da mesma é quase que totalmente explicada pela própria variável dependente. Passados 12 períodos, no entanto, ganham importância, ainda que relativamente pequena, a variação na renda mundial que segue todo o período relativamente superior ao da taxa de câmbio, revelando novamente a importância do cenário internacional para as exportações da soja brasileira.

Vale destacar o fato de que o efeito dos choques da renda mundial sobre as exportações vai se elevando ao longo de 12 períodos, passando de $2,5 \%$ para $3,6 \%$. Importante destacar ainda que, para a presente análise, também se adotou o ordenamento de Cholesky ( $r$ mund, $t$ _camb e $\left.x \_s o j a\right)$. Neste, a matriz de relações contemporâneas entre as variáveis do modelo impõe uma estrutura recursiva de modo que "a primeira variável não seja afetada contemporaneamente por nenhuma das demais, a segunda seja afetada apenas pela primeira, a terceira seja afetada pelas duas primeiras, e assim por diante", conforme Cavalcanti (2010).

\section{Considerações finais}

O mercado chinês vem se destacando como importante parceiro comercial brasileiro ao longo da década de 2000. O Brasil, nesse cenário, surge como tradicional fornecedor de commodities para o mercado mundial e tem aproveitado os bons momentos da expansão da demanda advindos das taxas de crescimento econômico da China. A pauta exportadora brasileira nos últimos anos tem registrado movimento em direção à primarização das exportações, e a China aparece como uma das principais responsáveis por esse efeito.

Diante deste panorama, viu-se que a soja tem despontado como produto de relevância na pauta exportadora brasileira para o mundo e, em especial, para a China. Os preços internacionais dessa commodity, por exemplo, contribuíram para alavancar o resultado positivo das transações comerciais desse produto nacional no comércio internacional, e a China teve papel fundamental nesse processo por ter puxado de forma expressiva a demanda por essa commodity. Em 2015, para se ter uma ideia, a venda de soja para esse país alcançou cerca de $75 \%$ do que foi exportado de soja para o mundo, revelando já possível importância da renda chinesa nos resultados comerciais do Brasil.

Assim, o presente artigo se propôs a analisar a possível existência de uma relação de longo prazo entre as variáveis taxa de câmbio efetiva real, renda mundial e as exportações brasileiras de soja em um cenário de importantes transformações e constatou que, no que se refere à análise de cointegração, as variáveis $x \_$soja,

Tabela 9. Resultados da decomposição da variância dos erros de previsão da variável Exportação de Soja (\%) - 2000 a 2015

\begin{tabular}{ccccc}
\hline Variável & Período & x_soja & r_mund & t_camb \\
\hline & 1 & 97,43357 & 2,565613 & 0,000821 \\
& 2 & 97,24675 & 2,349753 & 0,403495 \\
Ex_soja & 3 & 96,10423 & 3,176374 & 0,719396 \\
& 6 & 95,46857 & 3,595569 & 0,935863 \\
& 9 & 94,72177 & 3,602286 & 1,675943 \\
& 12 & 94,08109 & 3,648784 & 2,270123 \\
\hline
\end{tabular}

Fonte: Elaboração própria a partir dos dados da pesquisa, 2016. 
t_camb e r_mund têm uma relação de longo prazo, apresentando um vetor de cointegração. Nas estimativas de longo prazo do vetor de cointegração, a variável taxa de câmbio apresentou sinal contrário à teoria econômica; contudo, com coeficiente significativo. Já a variável renda mundial mostrou-se coerente com a teoria, apresentando elasticidade relativamente significativa.

Quanto à dinâmica de curto prazo, os valores dos coeficientes demonstram que a velocidade de ajustamento é baixa para as variáveis renda mundial e taxa de câmbio, ou seja, a correção no curto prazo se dá de maneira lenta para o equilíbrio cointegrante, ou de longo prazo. Ainda em relação à dinâmica de curto prazo, o termo de correção de erros indicou que, para a variável exportação, esses desequilíbrios são corrigidos de forma relativamente rápida.

$\mathrm{Na}$ análise das funções de impulso-resposta, por sua vez, o choque não antecipado de um desvio padrão na variável renda mundial gerou, inicialmente, uma queda acentuada no nível das exportações de soja já no primeiro período, seguindo, a partir daí, numa trajetória ascendente até o sétimo período, quando se estabiliza. Tal trajetória permite inferir que a variável renda mundial exerce alguma influência positiva sobre as exportações de soja. Quanto à ocorrência de um choque não antecipado sobre a variável taxa de câmbio, esta causa um efeito positivo sobre as exportações somente no segundo mês após o choque e, mesmo assim, de maneira relativamente baixa, estabilizando-se a partir do sétimo período.

Ademais, analisando os resultados da decomposição da variância dos erros de previsão para a variável exportação de soja, é possível observar que, nos primeiros períodos, a variância das exportações de soja é quase que totalmente explicada pela própria variável exportação de soja. Passados 12 períodos, no entanto, ganha importância, ainda que pouco significativa, a variação na renda mundial, que segue todo o período relativamente superior à taxa de câmbio, revelando, novamente a importância daquela variável no cenário internacional para as exportações da soja brasileira.

\section{Referências}

ALVES, L. R. A. e BACCHI, M. R. P. Oferta de exportação de açúcar do Brasil. Revista de Economia e Sociologia Rural, Brasília, DF, v. 42, n. 1, p. 9-33, 2004.
BRAGA, H. C. e MARKWALD, R. A. Funções de oferta $e$ de demanda das exportações de manufaturados no Brasil: estimação de um modelo simultâneo. (Texto para Discussão Interna, 57). Rio de Janeiro: Ipea, 1983.

BRASIL. Ministério do Desenvolvimento, Indústria e Comércio Exterior. Alice Web. Disponível em: <http:// aliceweb2.mdic.gov.br/> . Acesso em: out. 2016.

BUENO, R. de L. da S. Econometria de séries temporais. São Paulo: Cengage Learning, 2011.

CAMPBELL, J. Y. e PERRON, P. Pitfalls and opportunities: what macroeconomists should know about unit roots. In: BLANCHARD, O. J. e FISCHER, S. (Ed.). NBER Macroeconomics annual. Cambridge, CA: The MIT Press, 1991. p. 141-201.

CARNEIRO, F. L. A influência da taxa de câmbio sobre o desempenho comercial. 2013. Dissertação (Mestrado) Universidade de Brasília, Brasília, 2013.

CAVALCANTI, M. A. F. H. Identificação de modelos VAR e causalidade de Granger: uma nota de advertência. Economia Aplicada, v. 14, n. 2, Ribeirão Preto, abr.jun. 2010. Disponível em: <http:// www.scielo.br/scielo.php?script $=$ sci_arttext $\&$ pi $\mathrm{d}=$ S1413-80502010000200008 > . Acesso em: set. 2017.

. e RIBEIRO, M. A. As exportações no período 1977/96: desempenho e determinantes. (Texto para Discussão, 545). Brasília: Ipea, 1998.

COMPANHIA NACIONAL DE ABASTECIMENTO. Perspectivas para a agropecuária. Companhia Nacional de Abastecimento. Vol. 1. Brasília, 2015. Disponível em: <http://www.conab.gov.br>. Acesso em: nov. 2016.

COSTA JÚNIOR, C. J. Choques estocásticos na renda mundial e os efeitos na economia brasileira. Revista Economia E Tecnologia (RET), v. 9, n. 4, p. 51-60, out./ dez. 2013.

ENGLE, R. F. e GRANGER, C. W. J. Co-Integration and Error Correction: representation, estimation and testing. Econometrica, v. 55, n. 2, p. 251-276, 1987.

FABRIS, T. R. e MEURER, R. O comportamento de curto e longo prazo das exportações catarinenses. In: Encontro de Economia Catarinense, 1, 2007, Rio do Sul. Anais eletrônicos. Rio do Sul: APEC, 2007.

FREIRE JÚNIOR, J. e PAIVA, W. L. Efeitos da taxa de câmbio e da renda mundial sobre as exportações cearenses de produtos industrializados. (Textos para Discussão - $\mathrm{n}$ 은 103). Fortaleza, Ipece, 2014. Disponível em: <http:// www.ipece.ce.gov.br/textos_discussao/TD_103.pdf $>$. Acesso em: set. 2017.

FROYEN, R. T. MACROECONOMICS: theories and policies. Globa Editon. Tenth Edition. Pearson Education Limited, 2013. 
GUJARATI, D. N. Econometria básica. 4. ed. Tradução de Maria José Cyhlar Monteiro. Rio de Janeiro: Elsevier, 2006. INDEXMUNDI. Índice de preços da soja. Disponível em: $<$ http://www.indexmundi.com/pt/pre\% E7os-de-merc ado $/$ ?mercadoria $=$ soja\&meses $=180 \&$ mercadoria $=$ alg od\%C3\%A3o > . Acesso em: nov. 2016.

IPEADATA - Instituto de Pesquisa Econômica Aplicada. Série histórica. Disponível em: <www.ipeadata.gov. br>. Acesso em: dez. 2016.

JOHANSEN, S. Estimation and hypothesis test of coingration vector in Gaussian vector a autoregressive models. Econometrica, v. 59, p. 1551-1580, 1991.

LAMAS, E. Taxa de câmbio efetiva real para o Rio Grande do Sul - 1996-05. Indicadores Socioeconômicos FEE. Porto Alegre, v. 34, n. 3, p. 71-82, dez. 2006.

MAIA, S. F. Determinantes das exportações agrícolas em cenário de macroeconomia aberta: abordagem por modelos de séries de tempo. In: Encontro Nacional de Economia da Anpec, 31. 2003, Porto Seguro. Anais eletrônicos. Porto Seguro: ANPEC, 2003.

. e LIMA, R. C. Analisando o efeito da taxa de juros e da taxa de câmbio sobre as exportações agrícolas brasileira pós-abertura econômica. Recortes Setoriais da Economia Nordestina. Lúcia Maria Góis Moutinho (Org.). Fortaleza: CAEN/Banco do Nordeste do Brasil, 2004.

MARGARIDO, M. A. Aplicação de Testes de Raiz Unitária com Quebra Estrutural em Séries Econômicas no Brasil na década de 90. Informações Econômicas, São Paulo, v. 31, n. 4, abr. 2001.

MELO, M. C. P., BRAGA, F. L. P. e HOLANDA, D. H. O comércio exterior do nordeste brasileiro e seu fluxo caudatário. São Paulo: Editora Nelpa, 2014.

MELO, M. C. P. e HOLANDA, D. H. Implicações das Transações Comerciais da China com o Nordeste do Brasil: o caso da soja. Sociedade Brasileira de Economia, Administração e Sociologia Rural. Anais eletrônicos. Belém - PA, 21 a 24 de julho de 2013.

MONTE, E. Z. Influência da Taxa de Câmbio e da Renda Mundial nas Exportações do Estado do Espírito Santo. Análise Econômica, v. 63, n. 33, 2015. Disponível em: <http://seer.ufrgs.br/index.php/AnaliseEconomica/ article/view/31840 >. Acesso em: jan. 2017.

NAKABASHI, L., CRUZ, M. J. V. e SCATOLIN, F. D. Efeitos dos juros e do câmbio sobre as exportações da indústria brasileira. Revista de Economia Contemporânea, Rio de Janeiro, v. 12, n. 3, p. 433-461, set./dez. 2008. Disponível em: <www.scielo.br/pdf/rec/v12n3/02. pdf > . Acesso em: 11 mar. 2012.
NATIONAL STATISTICS REPUBLIC OF CHINA (Taiwan). Statistics by Categories. Wholesale Price Indices. Disponível em: <https://eng.stat.gov.tw/ ct.asp? $x$ Item $=12093 \&$ ct Node $=1558 \& m p=5>$. Acesso em: dez. 2016.

OLIVEIRA, A. C. S. Análise dos efeitos das taxas de câmbio, de juros e da renda mundial sobre as exportações brasileiras do mel brasileiro. 104f. Dissertação (Mestrado em Economia Rural) - Universidade Federal do Ceará, Fortaleza, 2013.

. et al. Análise dos efeitos das taxas de câmbio, de juros e da renda mundial sobre as exportações brasileiras de mel. Revista Econômica do Nordeste, v. 46, n. 3, p. 61-78, 2015.

PEREIRA, E. L., SILVA, J. R. e MAIA, S. F. Os efeitos da taxa de câmbio e dos Preços do Petróleo nos preços Internacionais das Commodities Brasileiras. Revista Econômica do Nordeste, Fortaleza, v. 48, n. 1, p. 131-144, 2017.

PORTUGAL, M. S. A instabilidade dos parâmetros nas equações de exportações brasileiras. Pesquisa $e$ Planejamento Econômico, Rio de Janeiro, v. 23, n. 2, p. 313-348, ago. 1993.

RAMALHO, H. M. de B. e TARGINO, I. A evolução das exportações brasileiras de cacau: uma análise do período 1950-2000. In: MOUTINHO, L. M. G. (Org.). Recortes setoriais da economia nordestina. Fortaleza: CAEN; Banco do Nordeste do Brasil, 2004.

SANDRONI, P. Dicionário de Economia do Século XXI. 8. ed. Rio de Janeiro: Record, 2014.

SILVA, E. K. e MAIA, S. F. As exportações brasileiras de café (1961-2001): uma análise usando vetores autoregressivos. In: Congresso da Sociedade Brasileira de Economia, Administração e Sociologia Rural, 41, Juiz de Fora. Anais eletrônicos. Juiz de Fora, 2003.

SILVA, M. V. S. S. e BACCHI, M. R. P. B. Condicionantes das exportações brasileiras de açúcar bruto. Agricultura em São Paulo, São Paulo, v. 52, n. 2, p. 99-110, 2005.

VERÍSSIMO, M. P. e SILVA, C. G. Taxa de Câmbio, Preços das Commodities e Exportação de Produtos Básicos nas Regiões Brasileiras. Revista Econômica do Nordeste, Fortaleza, v. 44, n. 3, p. 777-794, 2013.

WORLD BANK. Commodity price forecast, 2013. Disponível em: <www.worldbank.org/pt/country/ brazil>. Acesso em: fev./mar. 2016.

ZINI JÚNIOR, A. A. Funções de exportação e de importação para o Brasil. Pesquisa e Planejamento Econômico, Rio de Janeiro, v. 18, n. 3, p. 615-662, 1988.

Todo o conteúdo deste periódico, exceto onde estiver identificado, está licenciado sob uma Licença Creative Commons (cc by 4.0). 
